\title{
Physical properties improvement of the diesel engine lubricant oil reinforced nanomaterials
}

Nizar Jawad HADI, Rand Kareem Abd AL-HUSSAIN

DOI: 10.30464/jmee.2018.2.3.233

Cite this article as:

Hadi N. J., Al-Hussain R. K. A. Physical properties improvement of the diesel engine lubricant oil reinforced nanomaterials. Journal of Mechanical and Energy Engineering, Vol. 2(42), No. 3, 2018, pp. 233-244.

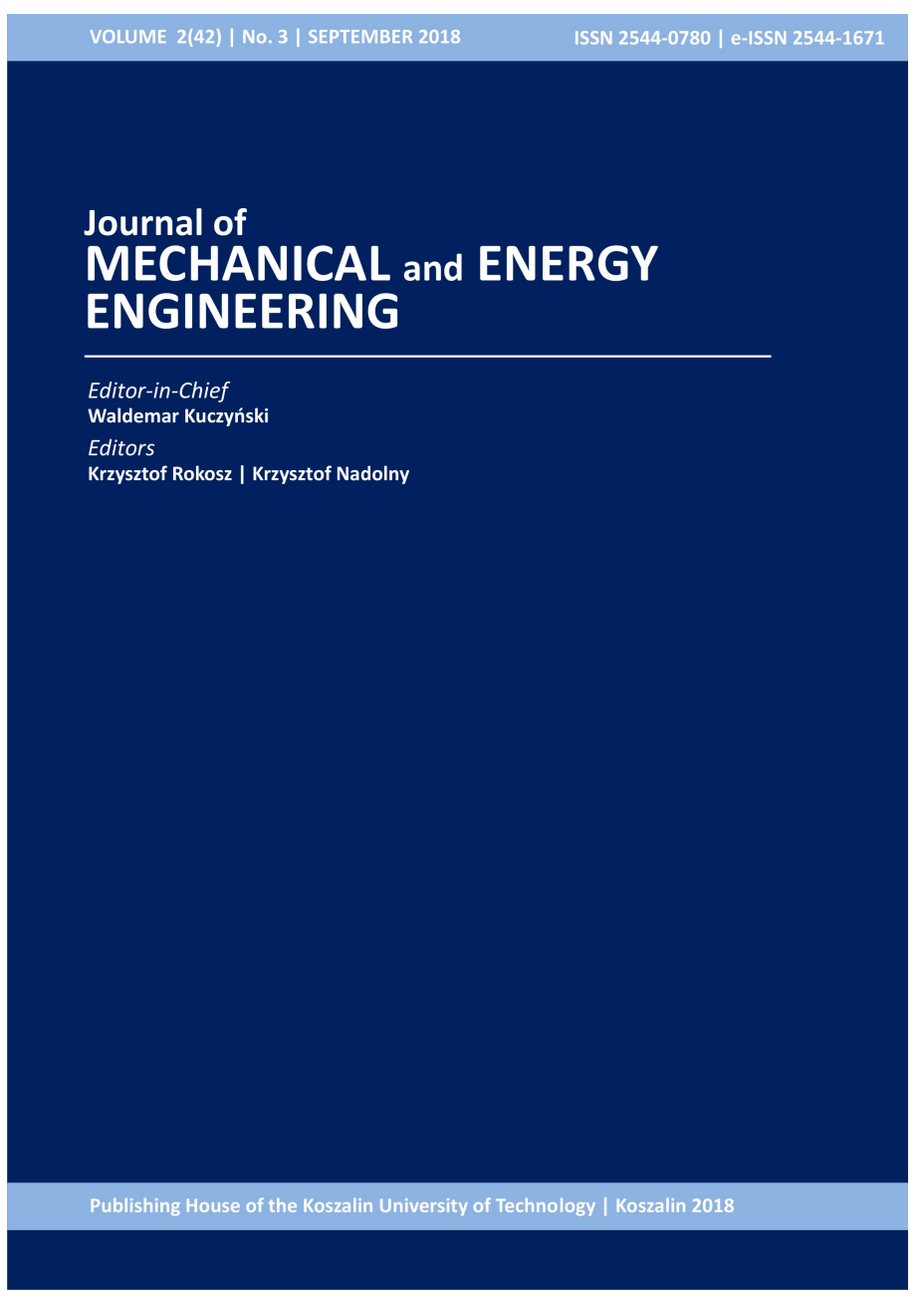

Journal of Mechanical and Energy Engineering

Website: jmee.tu.koszalin.pl

ISSN (Print): 2544-0780

ISSN (Online): 2544-1671

Volume: 2(42)

Number: 3

Year: 2018

Pages: 233-244

Article Info:

Received 16 August 2018

Accepted 20 September 2018

\section{Open Access}

This article is distributed under the terms of the Creative Commons Attribution 4.0 (CC BY 4.0) International License (http://creativecommons.org/licenses/by/4.0/), which permits unrestricted use, distribution, and reproduction in any medium, provided you give appropriate credit to the original author(s) and the source, provide a link to the Creative Commons license, and indicate if changes were made. 


\title{
PHYSICAL PROPERTIES IMPROVEMENT OF THE DIESEL ENGINE LUBRICANT OIL REINFORCED NANOMATERIALS
}

\author{
Nizar Jawad HADI ${ }^{* *}$, Rand Kareem Abd AL-HUSSAIN ${ }^{2}$ \\ ${ }^{1 *}$ Department of Polymer and Petrochemical Industries, College of Materials Engineering, University of \\ Babylon, Iraq, e-mail: nizarjawad63@uobabylon.edu.iq \\ ${ }^{2}$ Department of Polymer and Petrochemical Industries, College of Materials Engineering, University of \\ Babylon, Iraq, e-mail: randalmurshedy@yahoo.com
}

(Received 16 August 2018, Accepted 20 September 2018)

\begin{abstract}
This research focuses on the effect of nanomaterials on the physical properties of a local Iraqi lubricant oil (20W-50), which is widely used in diesel engines. The concentrations of $0.001,0.2$ and $0.5 \mathrm{wt} \%$ of $\mathrm{Al}_{2} \mathrm{O}_{3}$ NPs and CNT are dispersed in the oil with the help of a suitable surfactant using a magnetic stirrer and a sonication process. The density, surface tension, dynamic viscosity, kinematic viscosity, flash point, fire point, pour point, thermal conductivity, thermal images, wear and the coefficient of friction of the oil with and without nanomaterials are tested. The results were shown that the higher concentrations of NPs, the better properties for the engine oil. The density for $\mathrm{Al}_{2} \mathrm{O}_{3}$ nanooil indicates a small change at 0.001 and $0.2 \mathrm{wt} \%$, and a decrease at $0.5 \mathrm{wt} \%$ ratio. Also, the density of CNT oil shows a slight change at 0.001 and then decreasing at 0.2 and 0.5 ratios. In addition, the surface tension of both nanooils are increased. The dynamic viscosity slightly change with an addition of the NPs especially at $20^{\circ} \mathrm{C}$ and $30^{\circ} \mathrm{C}$. Also, there is a convergence in the viscosity values between base and nanooils at $40^{\circ} \mathrm{C}$ and $50^{\circ} \mathrm{C}$. Also, the dynamic viscosity indicates shear thickening behavior at low shear rate, while in the high shear rate the viscosity attempts to be more stable. The kinematic viscosity increases with an increased concentration of the NPs at $40^{\circ} \mathrm{C}$ and $100^{\circ} \mathrm{C}$ for both nanooils. The flash and fire point are increasing for both nanooils and $\mathrm{Al}_{2} \mathrm{O}_{3}$ nanooil indicates a lower pour point than that of CNT oil. CNT oil indicates higher dissipating heat friction and thermal conductivity than that of $\mathrm{Al}_{2} \mathrm{O}_{3}$ nanooil. Thermal images are supported by thermal conductivity and flash point behavior, while the tribology tests are compatible with viscosity behavior. A significant reduction in the coefficient of friction and wear loss is produced for both nanooils.
\end{abstract}

Keywords: Lubricant oil, Nano Fluid, Viscosity, Thermal conductivity, thermal images and Tribology

\section{INTRODUCTION}

Lubricant oil plays an important role in the production of pollution in lubrication, cooling and combustion systems. Nanomaterial used as additives to enhance the physical properties, improve the wear resistance, increase power vehicle, reduce the harmful emission and improve the thermal and flow behavior. Lubricant is characterized as a substance presented between two surfaces in relative movement to anticipate contact, enhance proficiency and decrease wear [1]. The properties of lubricating oil are modified by the use of different sorts of additives. This substances are chemical compounds added to lubricant oils to provide particular properties to oils. The added substances such as a viscosity improver, an anti-wear added substance, a friction reducer, rust/erosion inhibitors deal with grinding and wear properties [2]. Metal oxide nano-particales have been extensively developed in the last decades (ten years) [21]. In order to increase heat dissipation, the standard methodology is to expand the surface area accessible for the lubricant liquid. Nanoparticles, due to their unique 
properties, as a new kind of additive material for the purpose of improving the properties of lubricants, are very interesting and have attracted attention. So far, the anti-wear and anti-friction properties of different nanolubricants and also the heat transfer properties of fluids which contain different nanostructures have been studied by many researchers [3]. Nanotechnology could be used to enhance the possibilities of developing conventional and stranded gas resources and to improve the drilling process and oil and gas production by making it easier to separate oil and gas in the reservoir. Nanotechnology can make the oil and gas industry considerably greener [22].

Nano-fluids are a suspension of metallic or metaloxide solid nano -particles with sizes varying generally from 1 to $100 \mathrm{~nm}$, dispersed in conventional liquids such as water, ethylene glycol and engine oils etc. Nano-fluid technology is a new interdisciplinary field of great importance where nanoscience, nanotechnology and thermal engineering meet $[4,20]$. Rheology plays a critical part in the flow behavior of engines oils during preparation and manufacturing [5]. Viscosity modifiers or thickness index improvers as they were formally known, includes a class of materials that enhances the viscosity/temperature properties of the oil. This adjustment of rheological properties result in an expanded viscosity index of the motor oil. Viscosity modifiers are commonly oil solvable organic polymers with molecular weight running from around 10,000 to 1 million [6]. Throughout the years, numerous analysts centered their considerations to make new sorts of heat exchange liquids by suspending little (micrometer measured) particles in conventional fluids to improve their thermal transport performances [7]. Heat exchange liquids can show critical increments in thermal conductivity with an addition of highly conductive particles [8]. Since the thermal conductivities of most strong materials are higher than those of liquids, thermal conductivities of moleculeliquid blends are predictable to increase. Liquids with higher thermal conductivities would have possibilities for some thermal organization applications [9].

The addition of less conductive aluminum oxide particles were reported to increase the resulting thermal conductivities of base liquids by up to $30 \%$ at molecule volume portion of $\mathrm{Al}_{2} \mathrm{O}_{3}$ of $5 \%$. Single walled carbon nanotubes are 100 times more stronger than steel at one-6th the weight, and their thermal conductivity is around 5-10 times greater than that of exceptionally conductive materials such as aluminum or copper $[8,15]$. Carbon nanotubes, because of their high thermal conductivity coefficient, are famous as a perfect material for the production of nanofluids [3]. A reduction in the friction coefficient and worn scar depth was seen by an addition of nanoparticles to motor oil. It is concluded that viscosity impact is one reason for the friction coefficient reduction [10]. In tribology, some nanomaterials were added into lubricating oil to enhance extreme pressure, wear resistance and friction decrease properties [11]. The tribological properties of $\mathrm{TiO}_{2}, \mathrm{LaF}_{3}$, Graphite, Poly tetrafluoroethylene (PTFE), $\mathrm{MoS}_{2}, \mathrm{La}(\mathrm{OH})_{3}, \mathrm{PbS}$, Lanthanum Borate,Titanium Borate, Zinc Borate, Ferrous Borate, $\mathrm{Ni}, \mathrm{CaCO}_{3}$ and $\mathrm{ZnO}$ NPs utilized as added substances as a part of oil have been examined. Results demonstrate that they can deposit on the rubbing surface and enhance the tribological properties of the base oil [12]. Concentration of nanoparticles in oil is, obviously, a critical parameter. Low concentration of NPs is adequate to enhance the erosion and wear behavior [13]. A decrease of friction and wear leads to increase in service life, less downtime and lower working expenses [14].

Mohammadhassan Vasheghani and et al [16] Thermal conductivity of $\alpha-\mathrm{Al}_{2} \mathrm{O}_{3}$ was measured using the hot wire method. $\alpha-\mathrm{Al}_{2} \mathrm{O}_{3}(20 \mathrm{~nm}$ in size) was synthesized by the microwave method for which, the results were compared with commercially available $\gamma$ $\mathrm{Al}_{2} \mathrm{O}_{3}$. The thermal conductivity of nanofluids was investigated considering its dependency on the $\mathrm{Al}_{2} \mathrm{O}_{3}$ phase. It was observed that by adding $3 \mathrm{wt} \%$ of nano $\gamma-\mathrm{Al}_{2} \mathrm{O}_{3}$ and $\alpha-\mathrm{Al}_{2} \mathrm{O}_{3}$ to engine oil, thermal conductivity increases by 37 and $31 \%$, respectively. The corresponding viscosity increases for the same amount of nano $\gamma-\mathrm{Al}_{2} \mathrm{O}_{3}$ and $\alpha-\mathrm{Al}_{2} \mathrm{O}_{3}$ were 36 and $38 \%$, respectively. It was concluded that the differences in thermal conductivity originate from a higher specific surface area of $\gamma-\mathrm{Al}_{2} \mathrm{O}_{3}$ compared to the $\alpha-\mathrm{Al}_{2} \mathrm{O}_{3}$ which is the result of porosity difference, obtained during the synthesis process.

A.Hernández Battez and et.al. [17] This work presents and discusses the antiwear behaviour of nanoparticlesuspensions in a polyalphaolefin (PAO 6). $\mathrm{CuO}, \mathrm{ZnO}$ and $\mathrm{ZrO}_{2}$ nanoparticles were separately dispersed at $0.5 \%, 1.0 \%$ and $2.0 \%$ wt. in PAO 6 using an ultrasonic probe for $2 \mathrm{~min}$. AW properties were obtained using a TE53SLIM tribometer with a blockon-ring configuration. Tests were made under a load of $165 \mathrm{~N}$, sliding speed of $2 \mathrm{~m} / \mathrm{s}$ and a total distance of $3.066 \mathrm{~m}$. Wear surfaces were analysed by scanning electron microscopy and energy dispersive spectrometry (EDS) after wear tests. The study led to the following conclusions: all nanoparticle suspensions exhibited reductions in friction and wear compared to the base oil; the suspensions with $0.5 \%$ of $\mathrm{ZnO}$ and $\mathrm{ZrO}_{2}$ had the best general tribological behaviour, exhibiting high friction and wear reduction values even at low deposition levels on the wear surface; $\mathrm{CuO}$ suspensions showed the highest friction coefficient and the lowest wear per nanoparticle content of $2 \%$; and the antiwear mechanism of nanoparticulate additive was produced by tribosintering. 
The aim of this work is the enhancement of the flow, thermal and tribological properties of a diesel engine oil by mixing it with different ratios of NPs and CNT. Different percentages of $\mathrm{Al}_{2} \mathrm{O}_{3}$ NPs and CNT are mixed with a local Iraqi lubricant oil (20W-50) by using magnetic stirrer and sonication process. Different properties such as density, surface tension, dynamic viscosity, kinematic viscosity, flash point, fire point, pour point thermal conductivity thermal images and wear and friction coefficient with and without nanomaterials are tested. These different tests are supported by each other quantitatively and qualitatively, for example in viscosity and thermal behavior.

\section{MATERIALS AND METHODS}

The materials used in this study include a local lubricant oil (20W-50) provided from Al-doura station, which is widely used in diesel engines. Alumina $\left(\mathrm{Al}_{2} \mathrm{O}_{3}\right)$ with the diameter of $(39.3 \mathrm{~nm})$ and single walled carbon nanotube (SWCNT) with the diameter (0.6-1.1 $\mathrm{nm})$ are provided from (HWNANO/CHINA). The density, surface tension, dynamic viscosity, kinematic viscosity, flash point, fire point, pour point, thermal conductivity, thermal images, wear and the coefficient of friction of the oil with and without NPs are tested. Oleic acid as a surfactant is provided as a liquid by Central Drug Huse (P) LTD.7/28 Vardaan House, Daryaganj,New Delhi-110002 (INDIA). The properties of base oil, and Oleic acid are shown in the tables (1 and 2).

Tab. 1. Properties of a local Iraqi lubricant oil

\begin{tabular}{ll}
\hline Property & Value \\
\hline Density g/cm3 & 0.8036 \\
\hline Flash point ${ }^{\circ} \mathrm{C}$ & 205 \\
\hline Fire point ${ }^{\circ} \mathrm{C}$ & 210 \\
\hline Surface tension $(\mathrm{mN} / \mathrm{m})$ & 26.46 \\
\hline Pour point & -16 \\
\hline Dynamic viscosity $(\mathrm{cp})$ & 478.1 \\
\hline Kinematic viscosity $\left(\mathrm{mm}^{2} / \mathrm{sec}\right)$ at $40^{\circ} \mathrm{C}$ & 34.16 \\
\hline
\end{tabular}

Tab. 2. Properties of Oleic acid

\begin{tabular}{ll}
\hline Description & Yellowish to brown, oily clear liquid \\
\hline solubility & $\begin{array}{l}\text { Soluble in alcohol, chloroform \&in } \\
\text { ether }\end{array}$ \\
\hline Iodine value & $90-105$ \\
\hline Acid value & $195-204$ \\
\hline Peroxide value & 10.0 \\
\hline
\end{tabular}

\section{PREPARATION OF NANOOIL}

The method of the preparation of the nanooils includes the following steps.

1. Using glove box consisting of balance and vacuum conditional to mix the lubricant oil and nano materials.

2. Weighing $(0.001,0.2$ and $0.5 \mathrm{wt} \%)$ of $\mathrm{Al}_{2} \mathrm{O}_{3} \mathrm{NPs}$ and SWCNT and mixed with $150 \mathrm{ml}$ of base oil in glove box in order to prepare the nanooil.

3. Weighing of $0.3 \mathrm{wt} \%$ of Oleic acid as a surfactant and mixing with the nanooil.

4. Mixing the resulting oil by using the magnetic stirrer for $20 \mathrm{~min}$. at the room temperature and an ultrasonic device for $30 \mathrm{~min}$. at $50^{\circ} \mathrm{C}$ and 480 watt.

\section{CHARACTERIZATIONS}

\subsection{Density}

The measuring of density was performed at room temperature by using (matsu haku high precision density tester gp-12os), and the all experiment was calculated according to the Archimedes law.

\subsection{Surface tension}

The surface tension of the samples is measured by using JZYW-2008 automatic interface Tensiometer supply by being united test co., ltd.

\subsection{Rheology Test}

\section{Dynamic viscosity (cone-plate viscometer)}

The dynamic viscosity of the samples is examined using a cone - plate viscometer (DV- III ultra programmable rheometer) with the cone diameter of $4.8 \mathrm{~cm}$ and the cone angle of $3^{\circ}$ degree.

\section{Kinematic viscosity}

Kinematic viscosity was measured according to SYD - 265C ( petroleum products kinematic viscosity tester ) for each samples of lubricant oil by using viscometer at 40 and $100^{\circ} \mathrm{C}$. Kinematic viscosity can be calculated from the following equation:

$$
v=c \cdot t
$$

where:

v: kinematic viscosity $\left(\mathrm{mm}^{2} / \mathrm{s}\right)$

$\mathrm{c}$ : nominal viscometer constant $\left(\mathrm{mm}^{2} / \mathrm{s}^{2}\right)$

$\mathrm{t}$ : time required to passing the oil through limited marks in the viscometer (s)

For the base lubricant oil, the kinematic viscosity at $40^{\circ} \mathrm{C}$ and $100^{\circ} \mathrm{C}$ respectively is calculated as follows:

$$
\begin{gathered}
\text { At } 40^{\circ} \mathrm{C} v=c \times t=2.6 \times 49.9=29.74 \mathrm{~mm}^{2} / \mathrm{s} \\
\text { At } 100^{\circ} \mathrm{C} v=2.6 \times 10.5=27.3 \mathrm{~mm}^{2} / \mathrm{s}
\end{gathered}
$$

\section{Pour point}

All the samples were tested by using GD-510D Petroleum products pour point \& cloud point tester 


\section{Flash and Fire point}

All the samples in this test are examined using SYD3536 flash point and a fire point device. Approximately $70 \mathrm{~mL}$ of the oil test specimen is filled into a test cup. The temperature of the oil is increased rapidly and then it maintains at a constant rate increasing as the flash point is reached. At specified intervals, a test flame is passed across the cup to check the fire point.

\subsection{Thermal Test}

Thermal conductivity

There are many methods to find out the thermal conductivity of nanofluid and the transient hot-wire method. KD2 is the best suited method for that. The thermal conductivity is measured by using a KD2 Pro thermal properties analyzer (Decagon Devices, Inc., USA).

\section{Thermal Camera}

The thermal images are captured during the coefficient of friction test for each oil samples with and without the nanomaterials. The thermal analyzing of the oil layer in the contact region of a bin on the isk in the tribological test is examined by using the FLIR T6xx series camera as shown in Fig.1. Each image is captured for each three minutes of the test and the distance between the camera and the contact region of the bin on the disk is $47 \mathrm{~cm}$ as shown in the Fig.2. The spots locations in the contact zone of the pin on the disk device where the thermal imager are captured are shown in Fig. 3.

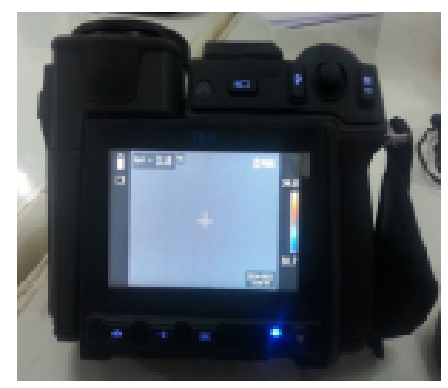

Fig. 1. FLIR Thermal

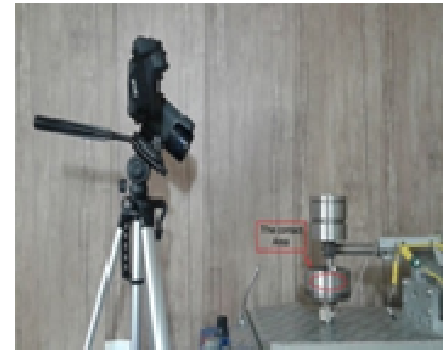

Fig. 2. Thermal camera location with respect to the contact zone

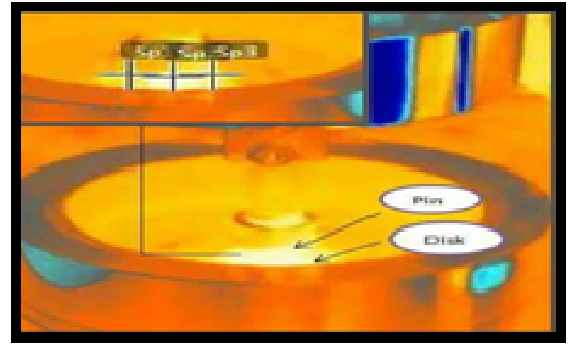

Fig. 3. The spots locations in the contact zone of pin on disk device where thermal images captured in each wear test

\section{Tribology test}

Wear and the coefficient of friction are examined by using the pin on the disk device (ASTM G99, MODEL 28021- MADRIED SPAN) as shown in Fig. 4. In this test, the upper ball was fixed and the lower disk was rotating. The pin specimen (the upper sample) was AISI 52100 steel ball, with $4 \mathrm{~mm}$ dimeter,roughness $0.952 \mathrm{Mm}$ and a hardness of 838 HV. The disk specimen (the lower sample) was made from tin and bromide and it represents the bearing part of the diesel engine with $(2.5 \mathrm{~cm}$ long x $2 \mathrm{~cm}$ width), $0.440 \mathrm{Mm}$ roughness and 210.9 $\mathrm{HV}$ hardness. All the tests were carried out under $25 \mathrm{~N}, 35 \mathrm{~N}$ and $45 \mathrm{~N}$, where the disk rotating at constant speed of $300 \mathrm{rpm}$ at the room temperature for $15 \mathrm{~min}$. The temperature of friction in the contact region measured by the thermal camera (FLIR T6xx) and checked with an infrared thermometer (smart sensor AR872D).

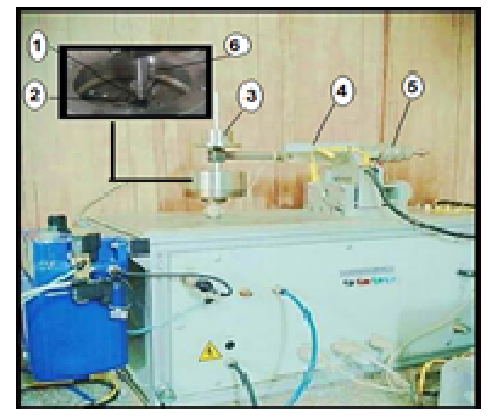

Fig. 4. Pin-on-Disc Sliding Machine

\section{DENSITY}

Fig 5.,shows that the density keeps stable at low concentration and decreases at the high concentration of nanomaterials addition for both nanooils. The density for $\mathrm{Al}_{2} \mathrm{O}_{3}$ nanooil indicates a small change at 0.001 and $0.2 \mathrm{wt} \%$, and decreasing at $0.5 \mathrm{wt} \%$ ratio. While, the density of CNT oil shows a slight change at 0.001 and then decreasing at 0.2 and 0.5 ratios. The reason behind that is the ability of nanomaterials to inter the spaces between the lubricant chains, which reduces the free volume space and restrains movement there. The increased density of the oil can lead to 
many of problems, including: the possibility of corrosion. In high turbulence or in high velocity regions of the system, the fluid can initiate to erode the surface that faces such as pipes and valves. The oxidation progresses with the increasing the density of the oil. Therefore, the reduction in density reduces this problem and simplifies the transportation operation.

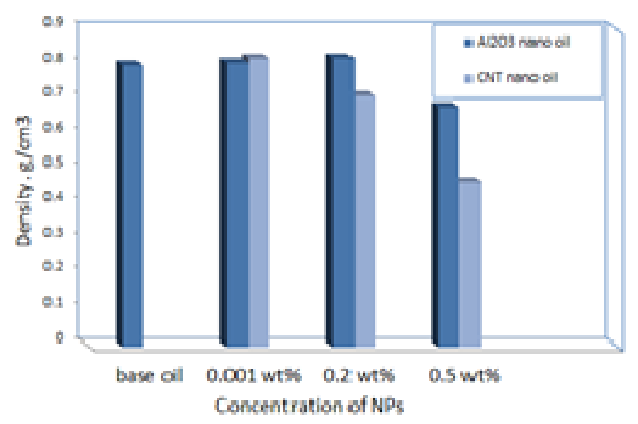

Fig. 5. Density behavior of lubricant oil as a function of $\mathrm{CNT}$ and $\mathrm{Al}_{2} \mathrm{O}_{3}$ NPs at different concentrations.

\section{SURFACE TENSION:}

Fig. 6 shows that the surface tension increases with the addition of both types of nanomaterials compared with the base oil. CNT nanooil indicates higher surface tension than that of $\mathrm{Al}_{2} \mathrm{O}_{3}$ nanooil at $0.001 \mathrm{wt} \%$, while, the $\mathrm{Al}_{2} \mathrm{O}_{3}$ nanooil indicates higher surface tension at 0.2 and $0.5 \mathrm{wt} \%$. The reason behind that is the Van der Waals forces between the NPs that increase the surface free energy and the attraction force between surface molecules. The oil must possess high surface tension relatively because when the oil is polluted, the surface tension decreases. This has an adverse affect on the oil's properties such as loss of antirust performance, foaming problems and increased leakage. The nanomaterials and surfactant produce the final surface tension behavior. The nanomaterials increase the surface tension due to the high free surface energy of NPs and CNT, while the surfactant reduce the surface tension due to the isolated of nanomaterials by chains.

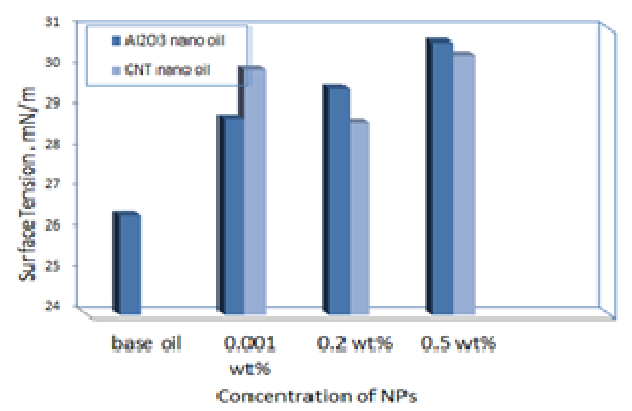

Fig. 6. Surface tension behavior of lubricant oil as a function of $\mathrm{CNT}$ and $\mathrm{Al}_{2} \mathrm{O}_{3}$ NPs at different concentrations.

\section{RHEOLOGICAL BEHAVIOR}

\subsection{Dynamic Viscosity}

\section{Temperature Effect}

Figs.7 and 8, show that the dynamic viscosity of each of the base oil and nanooils decreases with an increase of the temperature. This behavior is due to the decrease in the forces of cohesion between particles during heating. On the other hand, in general, dynamic viscosity increases with an increase of the concentration of NPs for both nanooils. This increase may belong to the agglomeration of NPs and it creates larger particles that prevent the oil movement. Additionally, there is rapid decreasing in viscosity from $20-40^{\circ} \mathrm{C}$ and, after $40^{\circ} \mathrm{C}$ up to $50^{\circ} \mathrm{C}$ the viscosity gradually decreases for both nanooils. This behavior means that the viscosity tends to be stable at higher temperatures. Also, the CNT oil indicates higher stability at $40^{\circ} \mathrm{C}$ than that of $\mathrm{Al}_{2} \mathrm{O}_{3}$ nanooil. Generally, the dynamic viscosity behavior of nanooils is very close to that of base oil This result gives a good indication for other properties which depend on the viscosity such as the coefficient of friction, the pour point and the movement of the oil inside the engine.

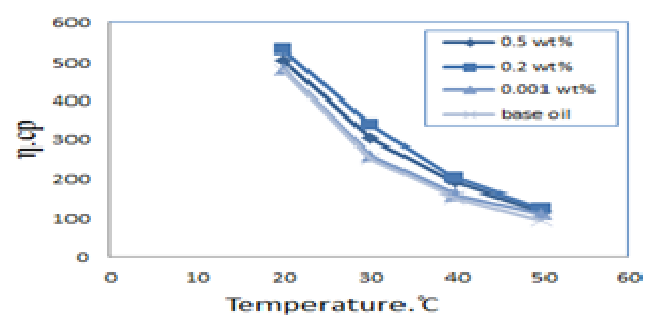

Fig. 7. Dynamic viscosity behavior of different concentrations of $\mathrm{Al}_{2} \mathrm{O}_{3}$ nanooil at different temperatutes

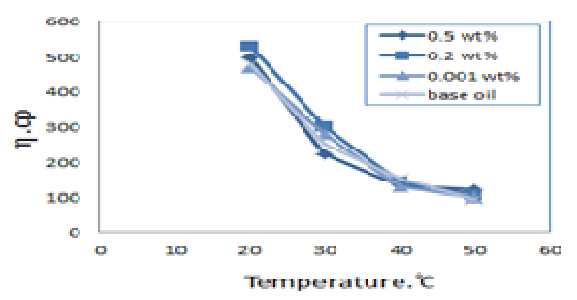

Fig.3: Dynarric riscosity behav.or of different conzentrations of CNT oil at different temperatures.

Fig. 8. Dynamic viscosity behavior of different concentrations of CNT oil at different temperatures

\section{Shear Rate Effect}

Figs. 9 and 10 show that the dynamic viscosity increases increase with an increase of the shear rate for each of base and nanooils. Also, shear thickening behavior was dominated at low shear rate. But this behavior attempts to be stable at high shear rate. Also, the dynamic viscosity of CNT nanooil is higher than 
that of $\mathrm{Al}_{2} \mathrm{O}_{3}$ nanooil. The $\mathrm{CNT}$ and $\mathrm{Al}_{2} \mathrm{O}_{3}$ nanooils indicate higher viscosity and stability at $0.2 \mathrm{wt} \%$ than that of the other ratios. The viscosity decreases at 0.5 wt $\%$ compared with $0.2 \mathrm{wt} \%$. In general, the dynamic viscosity of both nanooil increases with $\mathrm{Al}_{2} \mathrm{O}_{3}$ and CNT increases up to $0.2 \mathrm{wt} \%$ and then decreases

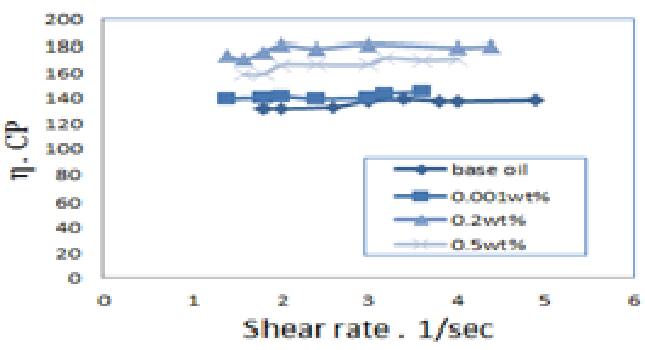

Fig. 9. Dynamic viscosity behavior of $\mathrm{Al}_{2} \mathrm{O}_{3}$ nanooil as a function of shear rate

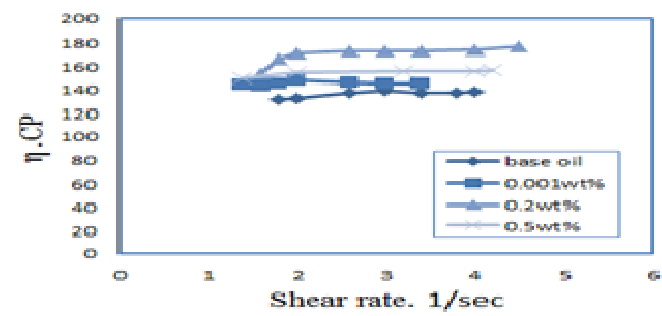

Fig. 10. Dynamic viscosity behavior of CNT oil as a function of shear rate

\subsection{Kinematic Viscosity}

Figs. 11 and 12 show the effect of an addition of the nanomaterials on the kinematic viscosity behavior of the base oil at $40^{\circ} \mathrm{C}$ and $100^{\circ} \mathrm{C}$ respectively. The kinematic viscosity of the base oil increases increase with an increase of the concentrations of the NPs at 40 and $100^{\circ} \mathrm{C}$. At $40^{\circ} \mathrm{C}$, the kinematic viscosity for CNT and $\mathrm{Al}_{2} \mathrm{O}_{3}$ nanooils indicate no change at 0.001 , while increasing at 0.2 and decreasing at $0.5 \mathrm{wt} \%$ ratio. This behavior may belong to the increase of density at $0.2 \mathrm{wt} \%$ and decreasing at $0.5 \mathrm{wt} \%$. The CNT oil indicates higher viscosity at $0.2 \mathrm{wt} \%$ than that of $\mathrm{AL}_{2} \mathrm{O}_{3}$ nanooil by about $22 \%$. Whereas, at $100^{\circ} \mathrm{C}$, the viscosity of the base oil decreases with the addition of the NPs, and the $\mathrm{Al}_{2} \mathrm{O}_{3}$ nanooil indicates higher viscosity than that of CNT oil at 0.2 and $0.5 \mathrm{wt} \%$. When the NPs are placed between the oil layers, this leads to the ease of oil layer movement on each other so the viscosity decreases, but when the concentrations of NPs increases, the viscosity increases due to the agglomeration of the NPs and creates larger particles which prevent movement of oil layers on each other this agreement with [18].

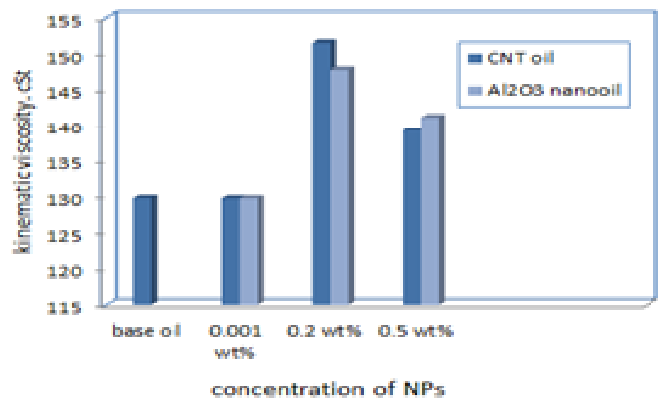

Fig. 11. Kinematic viscosity of base oil, $\mathrm{CNT}$ and $\mathrm{Al}_{2} \mathrm{O}_{3}$ nanooils at $40^{\circ} \mathrm{C}$

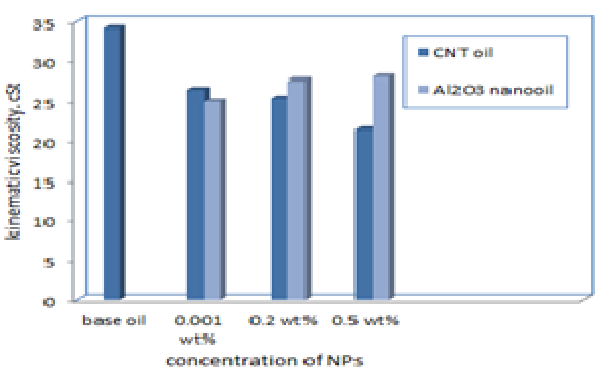

Fig. 12. Kinematic viscosity of base oil, $\mathrm{CNT}$ and $\mathrm{Al}_{2} \mathrm{O}_{3}$ nanooils at $100^{\circ} \mathrm{C}$

\subsection{Pour Point}

Fig.13, indicates the effect of the addition of CNT and $\mathrm{Al}_{2} \mathrm{O}_{3}$ NPs on the pour point behavior of the base oil. $\mathrm{Al}_{2} \mathrm{O}_{3}$ nanooil indicates lower pour point than that of CNT oil by $4 \%$ and $2 \%$ at 0.2 and $0.5 \mathrm{wt} \%$ respectively. Furthermore, the rate of the changes in the pour point at lower concentrations is much lower than that at higher concentrations. The pour point of base oil decreases with the addition of the NPs, this produces delay in the formation of crystals wax in the cooling oil and this result agree with that of Jamale[2] and Ehsan [3]. Generally, the change or the difference in the viscosity values compatible with results of the pour point. The CNT oil increases indicates higher viscosity than that of $\mathrm{Al}_{2} \mathrm{O}_{3}$ nanooil at $20^{\circ} \mathrm{C}$. For that, the CNT it accelerates the formation of wax crystals in the cooling oil at low temperatures and increases the pour point

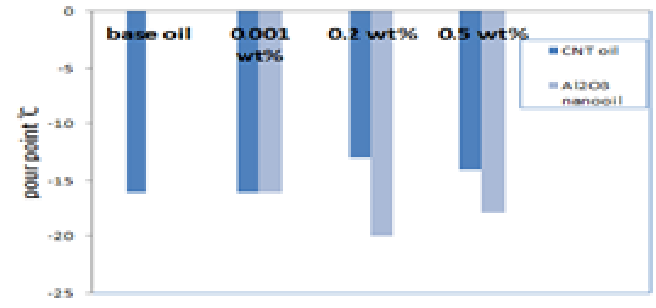

Fig. 13. Pour point behavior of base oil, $\mathrm{CNT}$ and $\mathrm{Al}_{2} \mathrm{O}_{3}$ nanooils at different concentrations 


\section{THERMAL BEHAVIOR}

\subsection{Thermal Conductivity}

Figs. 14 and 15, show the thermal condutivity behavior of base oil and both nanooils at different temperature and nanomaterials concentration. Fig. 14 shows that base oil thermal conductivity decreases between 20 to $40^{\circ} \mathrm{C}$, then increases up to $50^{\circ} \mathrm{C}$. The 0.001 and 0.5 nanooil between 20 and $30^{\circ} \mathrm{C}$ indicates an increase in thermal conductivity and then a decrease up to $50^{\circ} \mathrm{C}$. Also,the $0.2 \mathrm{wt} \% \mathrm{CNT}$ nanooil exhibits a decrease in thermal conductivity between 20 and $30^{\circ} \mathrm{C}$ and then it increases up to $50^{\circ} \mathrm{C}$. Fig. 15 indicates that the thermal conductivity increases with the $\mathrm{Al}_{2} \mathrm{O}_{3}$ NPs increase for all temperatures except of $0.5 \mathrm{wt} \%$ which decreases at $50^{\circ} \mathrm{C}$. In general, the thermal conductivity decreases between 20 to $40^{\circ} \mathrm{C}$ and then increases up to $50^{\circ} \mathrm{C}$. The $0.2 \mathrm{wt} \%$ of both nanooil indicates the optimum thermal conductivity behavior, while the $0.2 \mathrm{wt} \%$ CNT nanooil exhibits higher and suitable values than that of $0.2 \mathrm{wt} \% \mathrm{Al}_{2} \mathrm{O}_{3}$ nanooil, this result agrees with that of [19]

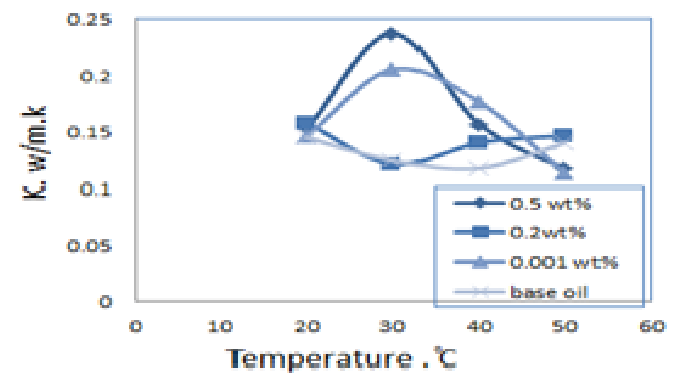

Fig. 14. Thermal conductivity behavior of base oil and CNT oil at different temperatures

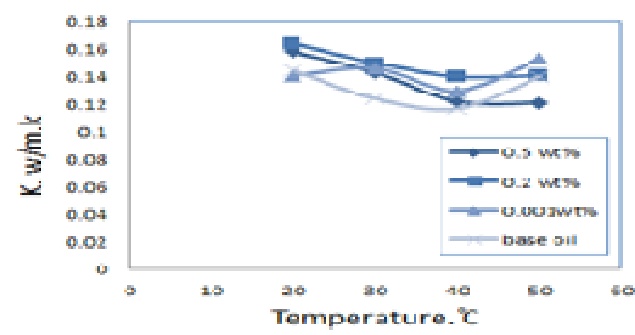

Fig. 15. Thermal conductivity behavior of base oil and $\mathrm{Al}_{2} \mathrm{O}_{3}$ nanooil as at different temperatures

\subsection{Thermal Images}

Figs.16 and 17 show the temperature behavior obseved by thermal images due to the heat of friction of the base oil with the addition of the NPs. The CNT oil indicates lower temperature than that of $\mathrm{Al}_{2} \mathrm{O}_{3}$ nanooil,this behavior $\mathrm{s}$ with the results of the thermal conductvity in Figs 14 and 15 and Srinivasan [13]. Fig. 16 shows a decrease in the temperature of base oil with an addition of the CNT at all concentrations. Also, CNT oil indicates lower heat of friction at 0.2 wt $\%$ than that of the other ratios. Fig. 17, shows a decrease in the temperature of base oil with the addition of the $\mathrm{Al}_{2} \mathrm{O}_{3}$ NPs and the lower heat of friction indicates at $0.001 \mathrm{wt} \%$. The, $\mathrm{Al}_{2} \mathrm{O}_{3}$ nanooil showed the same behavior of the base oil at 0.2 and $0.5 \mathrm{wt} \%$. Also, in general, the temperature increases for all samples of both nanooils with the load increasing.

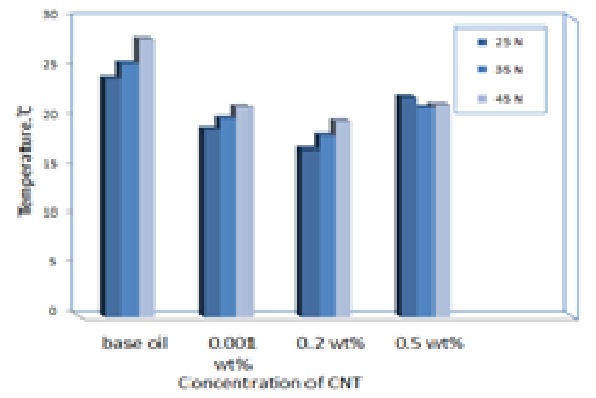

Fig. 16. Temperature behavior of different CNT oils during wear test under different loads

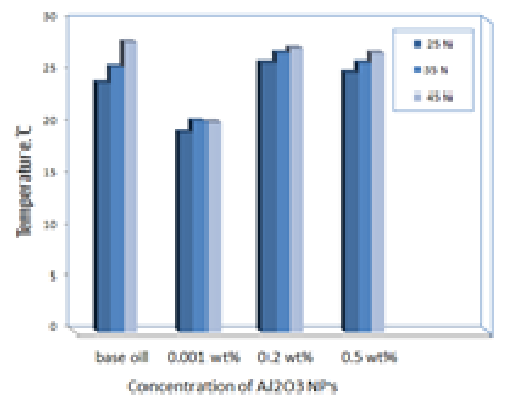

Fig. 17. Temperatures behavior of different $\mathrm{Al}_{2} \mathrm{O}_{3}$ nanooil during wear test under different loads

Figs. 18, 19, 20, 21, 22, 23 and 24 show the quantitative and qualitative thermal behavior in the contact zone of wear tests for base oil, CNT oils and $\mathrm{Al}_{2} \mathrm{O}_{3}$ nanooils. These images are captured at the sp1, sp2 and sp3 zones, which localized at Fig. 3. The qualitative thermal behavior indicates that the max. and min. magnitude of temperature for CNT oil reduced by about 6 and $9^{\circ} \mathrm{C}$ at low and high loads respectively compared with that of base oil. The qualitative thermal temperatures of $\mathrm{Al}_{2} \mathrm{O}_{3}$ nanooil at max. and min. reduce by about 7 and $2^{\circ} \mathrm{C}$ for 0.001 ratio and increase by $2^{\circ} \mathrm{C}$ for 0.2 and $0.5 \mathrm{wt} \%$ compared with base oil. 

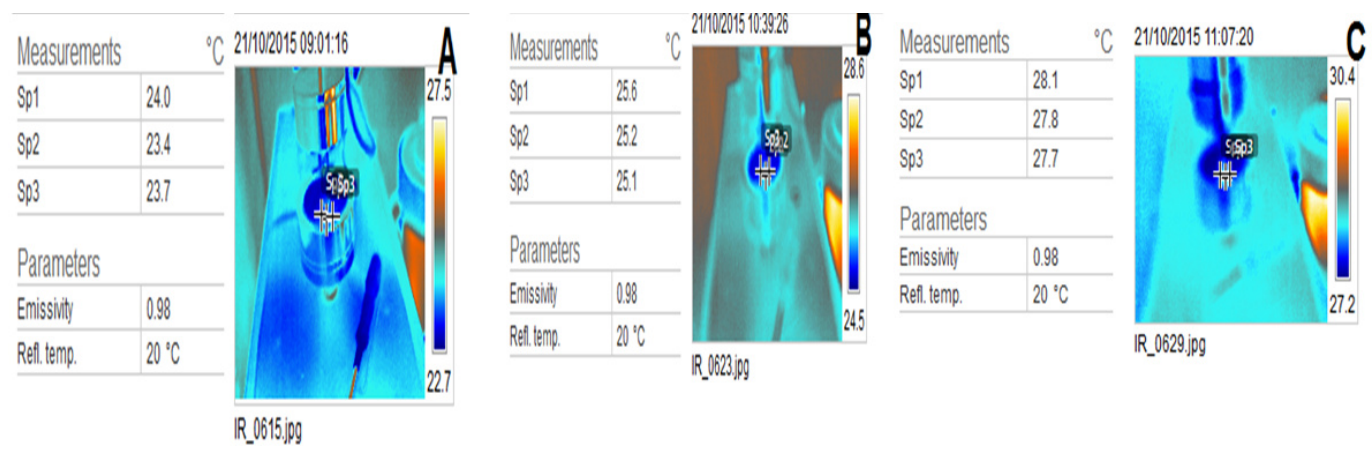

Fig. 18. The temperatures values of the base oil during the wear test under A) $25 \mathrm{~N}, \mathrm{~B}) 35 \mathrm{~N}$ and C) $45 \mathrm{~N}$
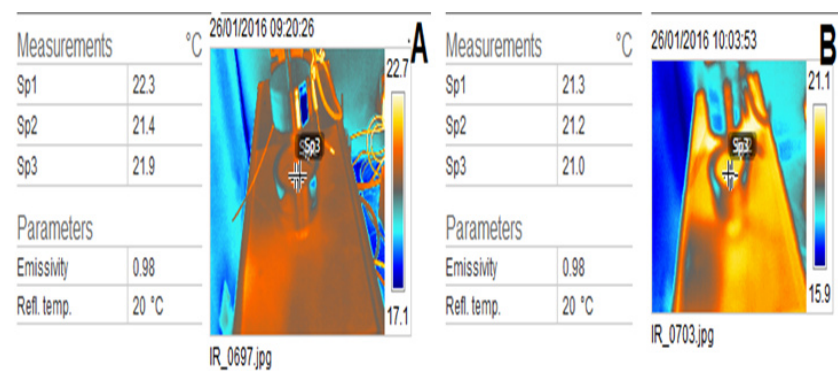

\begin{tabular}{l|l}
\hline Measurements & \multicolumn{2}{l}{${ }^{\circ} \mathrm{C}$} \\
\hline Sp1 & 21.5 \\
\hline Sp2 & 21.2 \\
\hline Sp3 & 20.5 \\
\hline Parameters \\
\hline Emissivity & 0.98 \\
\hline Refl. temp. & $20{ }^{\circ} \mathrm{C}$ \\
\hline
\end{tabular}

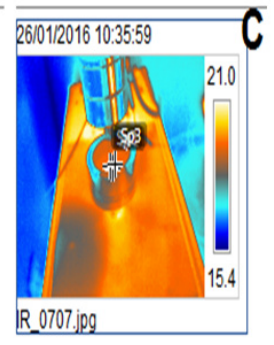

Fig. 19. The temperatures values of $0.001 \mathrm{wt} \% \mathrm{CNT}$ during the wear test under A) $25 \mathrm{~N}, \mathrm{~B}) 35 \mathrm{~N}$ and C) $45 \mathrm{~N}$

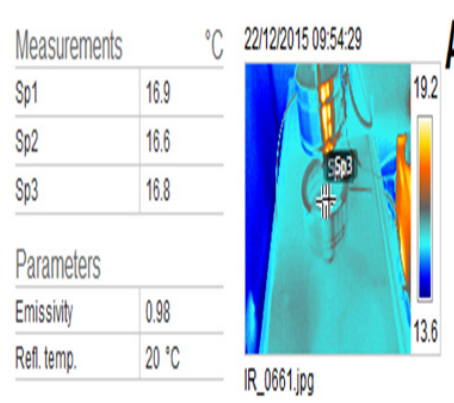

\begin{tabular}{|c|c|c|}
\hline \multicolumn{2}{|c|}{ Measurements } & C. 221122015 10:04:41 \\
\hline Spl & 18.3 & \\
\hline SPR & 17.8 & \\
\hline Sp3 & 17.9 & \\
\hline \multicolumn{2}{|c|}{ Parameters } & \\
\hline Emissinty & 0.98 & \\
\hline Refl temp. & $200^{\circ} \mathrm{C}$ & $\mathbb{R}_{-}$06663.jpg \\
\hline
\end{tabular}

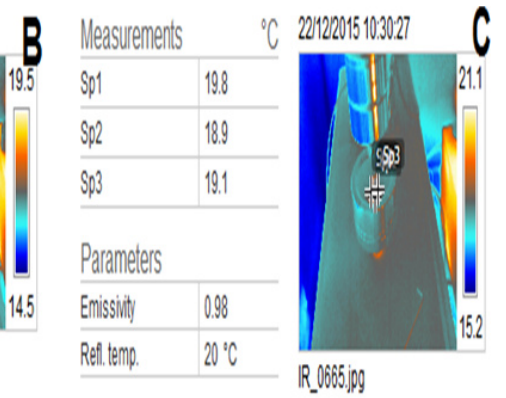

Fig. 20. The temperatures values of $0.2 \%$ CNT oil during the wear test under A) $25 \mathrm{~N}, \mathrm{~B}) 35 \mathrm{~N}$ and $\mathrm{C}) 45 \mathrm{~N}$
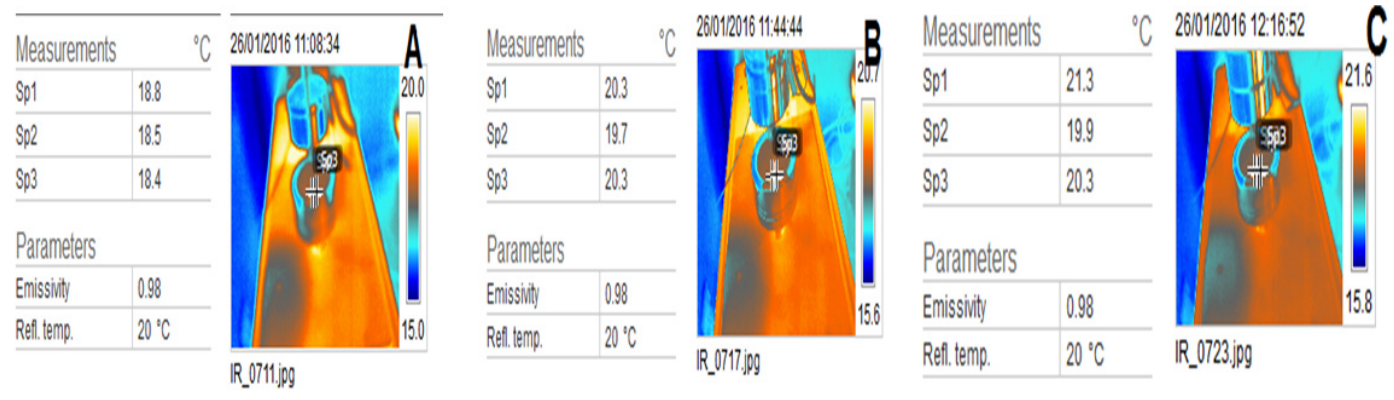

Fig. 21. The temperatures values of $0.5 \%$ CNT oil during the wear test under A) $25 \mathrm{~N}, \mathrm{~B}) 35 \mathrm{~N}$ and C) $45 \mathrm{~N}$ 

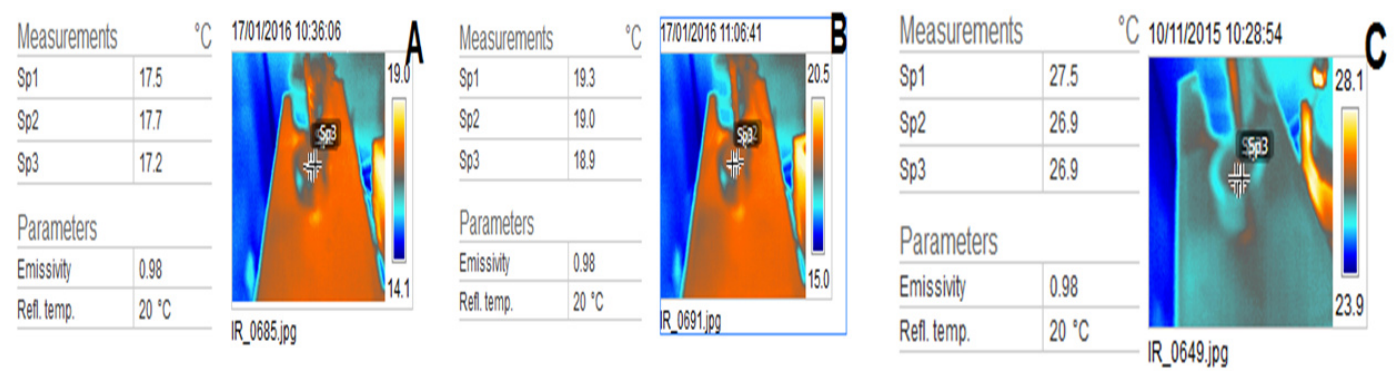

Fig. 22. The temperatures values of $0.001 \mathrm{wt} \% \mathrm{Al}_{2} \mathrm{O}_{3}$ nanooil during the wear test under A) $\left.25 \mathrm{~N}, \mathrm{~B}\right) 35 \mathrm{~N}$ and $\left.\mathrm{C}\right) 45 \mathrm{~N}$
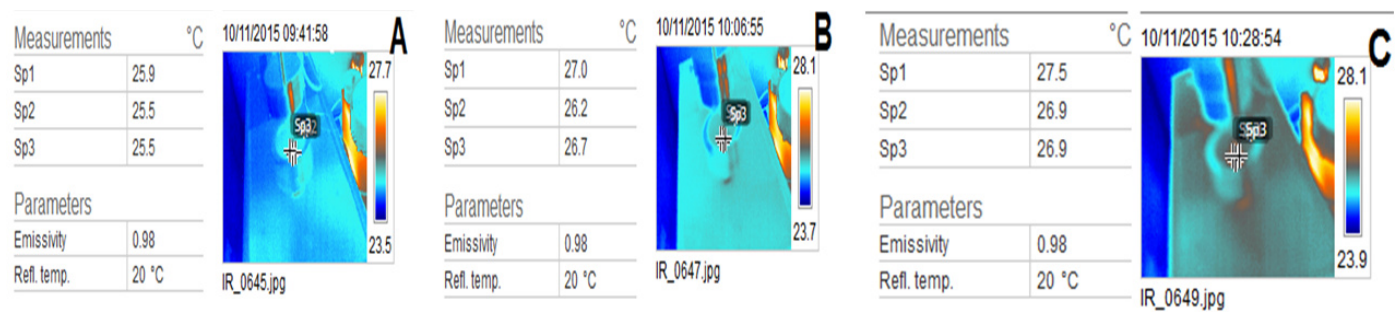

Fig. 23. The temperatures values of $0.2 \mathrm{wt} \% \mathrm{Al}_{2} \mathrm{O}_{3}$ nanooil during the wear test under A) $\left.25 \mathrm{~N}, \mathrm{~B}\right) 35 \mathrm{~N}$ and C) $45 \mathrm{~N}$
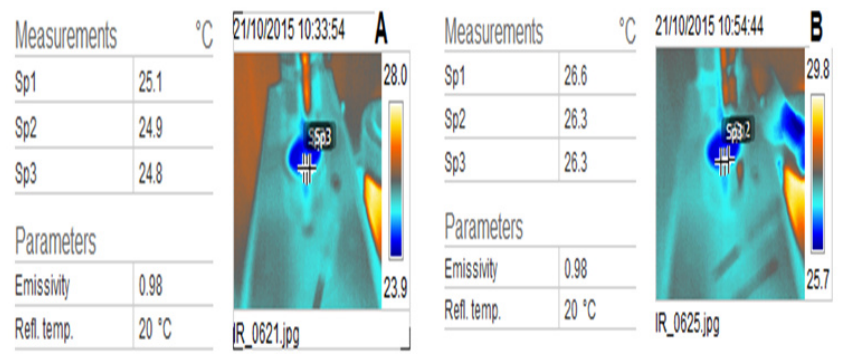

\begin{tabular}{|c|c|}
\hline \multicolumn{2}{|l|}{ Measure } \\
\hline Sp1 & 28.1 \\
\hline Sp2 & 28.1 \\
\hline SP3 & 27.9 \\
\hline \multicolumn{2}{|c|}{ Parameters } \\
\hline Emissivity & 0.98 \\
\hline Refl. temp. & $20^{\circ} \mathrm{C}$ \\
\hline
\end{tabular}

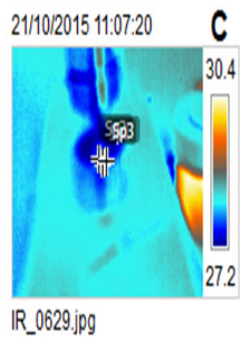

Fig. 24. The temperatures values of $0.5 \mathrm{wt} \% \mathrm{Al}_{2} \mathrm{O}_{3}$ nanooil during the wear test under A) $\left.25 \mathrm{~N}, \mathrm{~B}\right) 35 \mathrm{~N}$ and C) $45 \mathrm{~N}$

\section{FLASH AND FIRE POINT}

Fig. 25 and 26 show that the flash point and fire point increases for both nanooils respectively. The flash and fire point of the base oil increase increase with an increase of the concentration of the NPs. The CNT oil shows higher flash and fire point than that of the $\mathrm{Al}_{2} \mathrm{O}_{3}$ nanooil due to the higher thermal conductivity of CNT. Furthermore,the CNT oil indicates higher flash and fire point at $0.5 \mathrm{wt} \%$ by $35 \%$ and $40 \%$ respectively. The flash and fire points prove the compatability with the thermal conductivity and thermal images tests.

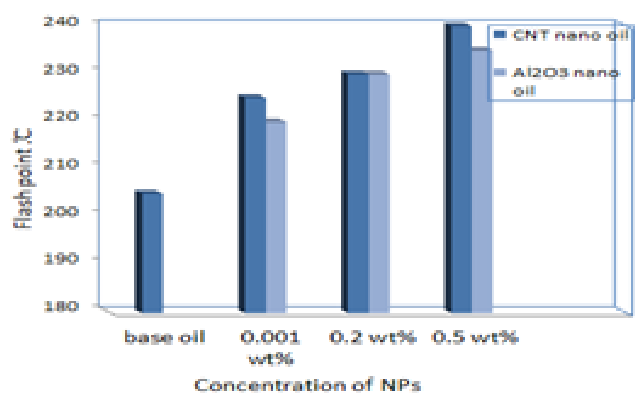

Fig. 25. Flash point behavior of base oil, CNT and $\mathrm{Al}_{2} \mathrm{O}_{3}$ nanooils at different concentrations 


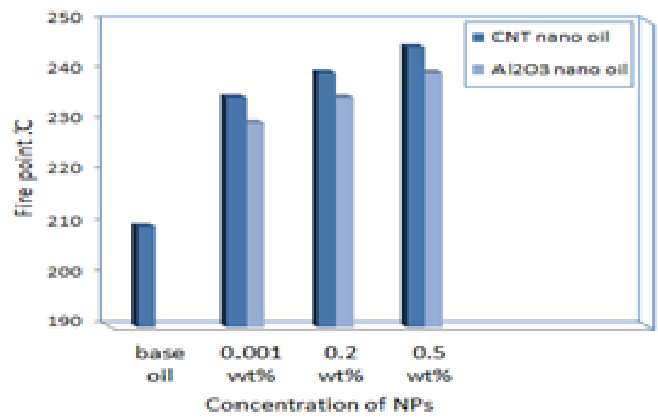

Fig. 26. Fire point behavior of base oil, $\mathrm{CNT}$ and $\mathrm{Al}_{2} \mathrm{O}_{3}$ nanooils at different concentrations

\section{TRIBOLOGICAL BEHAVIOR}

\subsection{Load Effect on Coefficient of Friction}

The friction coefficient and wear loss was measured by using the pin on disk tribotester under $10 \mathrm{~N}, 30 \mathrm{~N}$ and $50 \mathrm{~N}$ loads for 15 minutes at the room temperature and $300 \mathrm{rpm}$. Figs. 27 and 28 show a significant reduction in COF of the base oil with the addition of the NPs. This reduction is due to the NPs deposits on the contact surface and forming of a thin layer. Furthermore, if these NPs are unable to penetrate the contact area, their deposition on metal surface will be not effective, and the COF and the wear rate are increased. Also, the COF of the base and nanooils increases an increase of the applied load. However, the best ratio that reduces the COF is 0.5 $\mathrm{wt} \%$. The CNT oil indicates lower $\mathrm{COF}$ at $0.5 \mathrm{wt} \%$ than that of $\mathrm{Al}_{2} \mathrm{O}_{3}$ nanooil. Generally, a reduction of the COF of the base oil with the addition of the NPs agrees with the results of the dynamic viscosity. In addition, increasing the viscosity of the nanooils. reduces the surface friction. This means that the viscosity is inversely proportional with the COF.

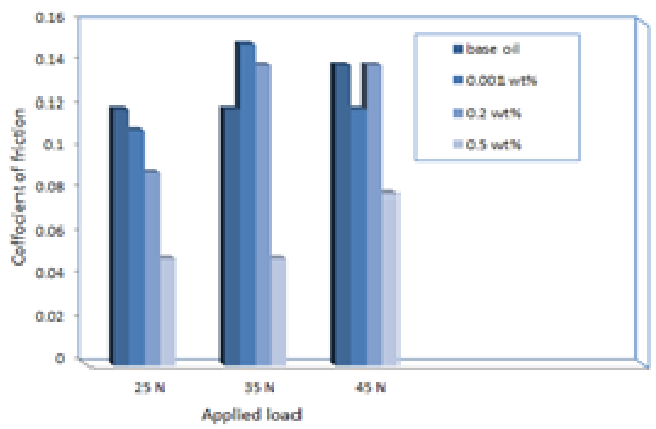

Fig. 27. Coefficient of friction as a function of load for different concentration of CNT oil

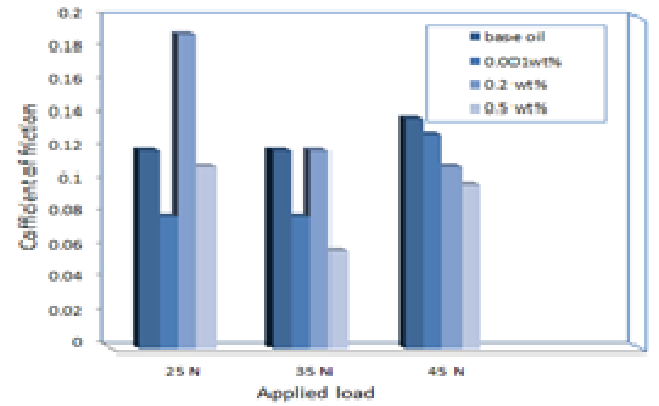

Fig. 28. Coefficient of friction as a function of load for different concentration of $\mathrm{Al}_{2} \mathrm{O}_{3}$ nanooil

\subsection{Load Effect On Wear Resistance}

Figs. 29 and 30 show that the wear loss of the base oil decreases at $35 \mathrm{~N}$ and then it increases at $45 \mathrm{~N}$. Fig.29 shows that the $0.01 \quad \mathrm{wt} \% \quad \mathrm{Al}_{2} \mathrm{O}_{3}$ nanooil indicates lower wear loss at $25 \mathrm{~N}$ and $45 \mathrm{~N}$ than that base oil, while it exhibits the same value at $35 \mathrm{~N}$. Also, $0.2 \mathrm{wt} \% \mathrm{Al}_{2} \mathrm{O}_{3}$ nanooil indicates lower wear loss than that base oil at $35 \mathrm{~N}$ and $45 \mathrm{~N}$, while in general $0.5 \mathrm{wt} \%$ shows higher wear loss compared with the base oil at all loads. Fig. 30 indicates that $0.001 \mathrm{wt} \%$ CNT nanooil exhibits approximately the same behavior of $0.001 \mathrm{wt} \% \mathrm{Al}_{2} \mathrm{O}_{3}$ nanooil. Also, $0.2 \mathrm{wt} \%$ CNT oil shows lower wear loss than that base oil at $25 \mathrm{~N}$ and $45 \mathrm{~N}$, while, $0.5 \mathrm{wt} \% \mathrm{CNT}$ oil produces lower wear loss than that base oil for all loads.

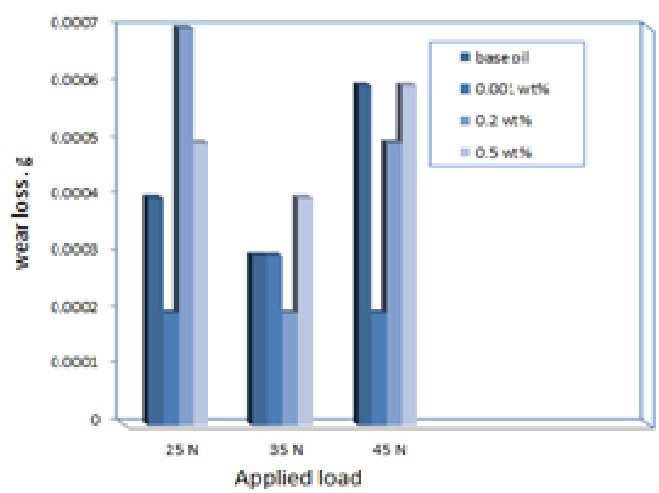

Fig. 29. Effect of $\mathrm{Al}_{2} \mathrm{O}_{3}$ nanooils on the wear resistance at different loads 


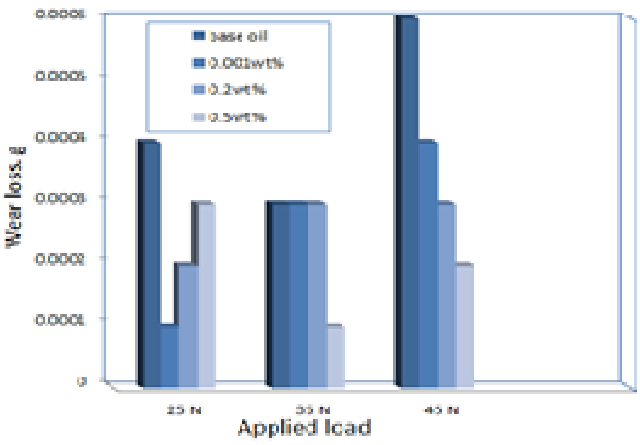

Fig. 30. Effect of CNT oils on the wear resistance at different loads

\section{CONCLUSIONS}

To study the advantages and disadvantages of dispersing nanomaterials in lubricant oil; different quantitative and qualititive tests must be performed. Size, shape and type of nanopartticles and nanotubes dispersed in oil have a strong effect on the performance of nanooil. Also, the stability of nanooil depending on the mixing process and surfactant type is another challange. In this research, we examined the different properties giving a comperhensive picture to the final improvement. For example, the density decrease of nanooil compatable with the viscosity increase. Also, thermal conductivity increase, quantitative and qualitative thermal behavior in thermal images. The reduction in cofficient of friction and wear loss of both nanooil support the relationship between the thermal and tribology behavior. Forthermore, the viscosity and surface tension related to the pour point.

From the analysis above, it can be concluded the following items.

1. The density for $\mathrm{Al}_{2} \mathrm{O}_{3}$ nanooil indicates a small change at 0.001 and $0.2 \mathrm{wt} \%$, and a decrease at 0.5 $\mathrm{wt} \%$ ratio. Also, the surface tension of both nanooils is increased due to the NPs and CNT presenting.

2. The dynamic and kinematic viscosity increase an increase of the concentration of the NPs. Furthermore, the CNT oil indicates higher stability at $40^{\circ} \mathrm{C}$ than that of $\mathrm{Al}_{2} \mathrm{O}_{3}$ nanooil. Also, the $\mathrm{Al}_{2} \mathrm{O}_{3}$ nanooil indicates lower pour point than that of CNT.

3. There is a direct relation between flash, fire point and the concentrations of NPs and thermal behavior. The CNT oil indicates more dissipating friction heat and higher thermal conductivity than that of $\mathrm{Al}_{2} \mathrm{O}_{3}$ nanooils.

4. Thermal images is an effective tool to check the thermal behavior of nanooil in contact zone. The results of thermal image indicate a decrease in the heat of friction of nanooil compared to the base oil. CNT oil indicates lower heat of friction than that of $\mathrm{Al}_{2} \mathrm{O}_{3}$ nanooil.

5. A significant reduction in the coefficient of friction and wear loss shown for all nanooil and the CNT oil indicates lower COF than that of $\mathrm{Al}_{2} \mathrm{O}_{3}$ nanooil at $0.5 \mathrm{wt} \%$.

\section{References}

1. Ahmed Awad and Shahad Mohammed, "A Study of Enhancement of the Properties of Lubricant Oil", American Journal of Chemistry,Vol.4,No.1,2014.

2. Jamale Sonali, Sandhyarani and Sajith, "Tribological properties and stabilization study of surfactant modified MoS2 nanoparticle in 15 W40 engine oil", International Journal of Fluid Mechanics \& MachineryIJFMM,Vol.1,2014.

3. Ehsan-o-llah Ettefaghi, Hojjat Ahmadi, Alimorad Rashidi, Seyed Saeid Mohtasebi and Mahshad Alaei" Experimental evaluation of engine oil properties containing copper oxide nanoparticles as a nanoadditive",International Journal of Industrial Chemistry, Vol.4, No.28,2013.

4. Kamaldeep Singh, Sumeet Sharma and Gangacharyulu "Experimental Study of Thermophysical Properties of $\mathrm{Al}_{2} \mathrm{O}_{3}$ /Water Nanofluid" International Journal of Research in Mechanical Engineering \& Technology Vol. 3, Issue 2, 2013.

5. Sabiha Tanveer, Umesh Chandra Sharma and Ram Prasad " Rheology of multigrade engine oils" Indian journal of Chemical Technology Vol. 13, PP.180-184, 2006.

6. Obasi, Udeagbara and Anusiobi " Effect of Additives on the Performance of Engine Oil" International Journal of Engineering and Technology Research,Vol. 2, No. 9, pp. $1-11,2014$.

7. Muhammad Khairuddin " Preparation of Copper Nano Lubricant for High End Application" Report submitted in partial fulfilment of the requirements for the award of the degree of Bachelor of Chemical Engineering, University Malaysia pahang, 2012.

8. Layth Ismael and Khalid Faisal," A comparative Study on the Thermal Conductivity of Micro and Nano fluids by Using Silver and Zirconium Oxide", Al-Qadisiya Journal For Engineering Sciences, Vol.7,No.2,2014.

9. Xinwei Wang and Xianfan Xu " Thermal Conductivity of Nanoparticle-Fluid Mixture", Journal of Thermophysics and Heat Transfer,Vol.13, No.4, 1999.

10. Motmaen Isfahania, Makarema, Ghotbia and Kashanib "Effects of sonicated nanoparticle additives on the engine oil properties" Proceedings of the 4th International Conference on Nanostructures (ICNS4) pp.12-14, Kish Island, I.R. Iran.2012.

11. Asrula, Zulkiflia, Masjukia and Kalama, "Tribological properties and lubricant mechanism of Nanoparticle in Engine Oil", Procedia Engineering,Vol.68, pp.320 - 325, 2013.

12. Zhenyu Zhang, Dorin Simionesie and Carl Schaschke Zhenyu Zhan, Dorin Simionesie and Carl Schaschke,“Lubricants”, Vol.2,pp. 44-65,2014.

13. Sajumon, Jubin Jose, Sreejith, Aghil Menon, Sreeraj Kurup and Sarath Sasi, "Performance Analysis of Nanofluid based Lubricant", International Journal of Innovative Research in Science, Engineering and Technology, Vol.2, 2013.

14. Magdi Abadir, Fatma El-Zahraa Ashour, Nehal Ahmed, Rasha Kamal and El-Shimaa El-Zahed, "The Effect of Some Additives on the Rheological Properties of Engine 
Lubricating Oil”, Journal of Engineering Research and Applications", Vol.4, pp.169-183,2014.

15. Srinivasan and Saraswathi," Nano-oil with high thermal conductivity and excellent electrical insulation properties for transformers ", Current Science, VOL. 102, NO. 10, 25, 2012.

16. Mohammad hassan Vasheghani, Ehsan Marzbanrad, Cyrus Zamani Mohamed Aminy,Babak Raissi, Toraj Ebadzadeh and Hadi Barzegar-Bafrooei"Effect of $\mathrm{Al}_{2} \mathrm{O}_{3}$ phases on the enhancement of thermal conductivity and viscosity of nanofluids in engine oil" Heat Mass Transfer Vol.47,pp.1401-1405,2011.

17. Hern'andez Battez,Gonz'alez,Viesca,Fern'andez, D'1az Fern’andez b, Machadoc and Choud, Riba," $\mathrm{CuO}, \mathrm{ZrO}_{2}$ and $\mathrm{ZnO}$ nanoparticles as antiwear additive in oil lubricants", Wear, vol. 265 pp. 422-428,2008.

18. Magdi Abadir, Fatma El-Zahraa Ashour, Nehal Ahmed, Rasha Kamal and El-Shimaa El-Zahed, "The Effect of Some Additives on the Rheological Properties of Engine Lubricating Oil", Journal of Engineering Research and Applications", Vol.4, pp.169-183,2014.

19. Lee S, Choi SUS, Li S, Eastman JA: Measuring thermal conductivity of fluids containing oxide nanoparticles. ASME J Heat Transfer 1999,121:280-89.

20. Wang XQ, Mujumdar AS: A review on nanofluids theoretical and numerical investigations. Braz J Chem Eng 2008, 25:613-630.3. Singh AK: Thermal conductivity of nanofluids. Defence Sci J 200858:600607

21. Akanksha Paraye Prof. (Mrs.) S. R.Mote "Synthesis of Alomina nano-particles and study of heat transfer enhancement". International Journal of engineering, Economics and Management : ISSN: 2319-7927, Volume 3, Issu.

22. Abdollah Esmaaeili “ A pplication of nano- technology in oil and gas industry" petrotech, 11-15 Januwary 2009,New Delhi.

\section{Biographical notes}

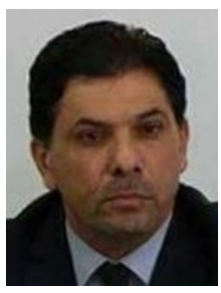

Nizar Jawad Hadi has worked in many areas of advanced engineering including Nano fluid, rheology of polymer, numerical simulation, and nanotechnology. He has participated as a member of various workshops and courses in Europe and the United States. He has served as a dean assistant for administration affairs and now he is a head of polymer and petrochemical industries department. He holds $\mathrm{PhD}$ in mechanical engineering/college of engineering in Baghdad University. He supervised twelve master and three Ph.D. students in the fields of rheology and nanotechnology. He has participated in twelve international conferences and ten local conferences. He has published more than thirty five papers in the international and local journals. He has participated in teaching of undergraduate and postgraduate students.

Rand Kareem; MSc, Graduate at 2016 from Polymer and Petrochemical Industries department, College of materials engineering, University of Babylon. Now she is a lecturer in the same department. Also she is work at the petro-chemical Labs. 